\title{
Evaluation of the shift to emergency remote learning of veterinary anatomy during the COVID-19 pandemic: A global students' perspectives
}

Mohamed A. A. Mahdy ( $\sim$ m_mahdi@vet.svu.edu.eg )

South Valley University https://orcid.org/0000-0001-6402-2944

\section{Research Article}

Keywords: Assessment, anatomy teaching, COVID-19, coronavirus, remote teaching, veterinary

Posted Date: June 28th, 2021

DOl: https://doi.org/10.21203/rs.3.rs-662248/v1

License: (c) (1) This work is licensed under a Creative Commons Attribution 4.0 International License.

Read Full License 


\section{Abstract}

Purpose: The present study assessed the shift to remote teaching of veterinary anatomy during the COVID-19 pandemic based on students' perspectives.

Methods: Participants were invited to answer an anonymous online Google Form questionnaire using the snowball sampling method. Only students who studied anatomy online during the COVID-19 lockdown period were eligible to answer the questionnaire.

Results: A total of 961 participants were enrolled in this study from 87 countries and 6 continents. Data showed that the majority of students (81.6\%) were interested in studying anatomy online during COVID19 lockdown. Moreover, approximately $82 \%$ of students were comfortable with the technological skills and approximately $61 \%$ of students can understand online anatomy well during lockdown. Furthermore, approximately $52.76 \%$ of students believed that online learning of anatomy suited for theoretical, $8.74 \%$ believed that it suited for practical parts, and $30.28 \%$ believed that it suited for both theoretical and practical parts. On the contrary, about $36.63 \%$ of students thought that online learning of anatomy could replace face-to-face teaching. In conclusion, shifting to remote teaching appears to be a good and convenient approach during the lockdown period as shown by student interest to study anatomy online during the COVID-19 lockdown, their comfortability with the technological skills, and their level of understanding. However, practical classes with cadaver dissection and dealing with different anatomical specimens is essential for veterinary students, therefore, blended learning is recommended.

Conclusion: the study highlighted several challenges associated with studying anatomy online during lockdown period and recommendation to overcome these challenges.

\section{Introduction}

An emerging coronavirus has been reported in Wuhan city, China in December 2019 as the causative agent of pneumonia cases with an unknown cause (Li, Guan et al. 2020, Mahdy, Younis et al. 2020). Later, World Health Organization (WHO) identified the disease as coronavirus disease 2019 (COVID-19) and announced it as a pandemic (WHO 2020) The disease spread rapidly to 222 countries with over 149 million confirmed cases and about 3 million deaths worldwide as of April 27 ${ }^{\text {th }}, 2020$ (WHO 2019), it greatly affected social, economic, and cultural life worldwide (Aristovnik, Keržič et al. 2020, Guan, Deng et al. 2020, Haleem, Javaid et al. 2020, Pak, Adegboye et al. 2020).

The worldwide educational systems have been greatly affected by COVID-19 pandemic affecting a maximum number of about 1.5 billion learners ( $84.3 \%$ of total enrolled learners) in 172 countries around the world as of April $1^{\text {st }}, 2020$ then the number decreased afterwards (UNESCO 2020). Therefore, preventive measures have been applied in the educational sector to stop the spread of COVID-19 including either temporary closure or implemented localized closures of schools, colleges, and universities to protect staff and students' health. This is accompanied by shifting of face-to-face teaching to online and remote learning modes (Brassett, Cosker et al. 2020, Singh, Gaur et al. 2020, Wahab 2020). 
The online teaching-learning during the pandemic period is considered a new experience for teachers, as well as students (Brassett, Cosker et al. 2020, Mishra, Gupta et al. 2020). Moreover, it tested the degree of readiness of the educational institutions worldwide (Singh, Gaur et al. 2020). Therefore, universities that had a previous experience with educational technologies, such as video-conferencing platforms were rapidly and successfully adapted (Aristovnik, Keržič et al. 2020, Brassett, Cosker et al. 2020, Pather, Blyth et al. 2020, Wahab 2020). On the contrary, many universities used online teaching for the first time after the emergence of COVID-19 pandemic (Aristovnik, Keržič et al. 2020, Cuschieri and Calleja Agius 2020).

Several studies worldwide have been carried out to investigate the influence of COVID-19 on the academic performance of university students (Aristovnik, Keržič et al. 2020, Baticulon, Alberto et al. 2020, Franchi 2020, Kapasia, Paul et al. 2020, Mahdy 2020, Marelli, Castelnuovo et al. 2020, Mishra, Gupta et al. 2020, Mukhtar, Javed et al. 2020, Pather, Blyth et al. 2020, Rashid, Rashid et al. 2020, Romero-Blanco, Rodríguez-Almagro et al. 2020). These studies showed that it is crucial for students to adapt to the new situation during COVID-19 pandemic (Baticulon, Alberto et al. 2020, Pather, Blyth et al. 2020). However, online learning is associated with several problems, such as availability, connectivity, cost and speed of internet, lack of electronic devices to access the online materials, and lack of effective communication between students and teachers (Brassett, Cosker et al. 2020, Mahdy 2020, Sahu 2020).

COVID-19 provided an opportunity for anatomists to switch from conventional methods of teaching anatomy to produce online learning resources that offer flexibility for learners, as well as educators (Brassett, Cosker et al. 2020, Byrnes, Kiely et al. 2020). However, it is challenging to teach anatomy online via virtual classes and distance learning. This abrupt shift to virtual mode needs extra efforts due to the lack of practical cadaver dissection, embryology models, bone specimens, microscopic slides, and face-to-face interaction with teachers. Moreover, it will have a great impact on students (Brassett, Cosker et al. 2020, Franchi 2020, Ross, Pescitelli et al. 2020, Singh, Gaur et al. 2020). The current situation provides an opportunity for a careful assessment of the strengths and weaknesses of the online teaching of anatomy and compare it with conventional teaching methods (Brassett, Cosker et al. 2020, Byrnes, Kiely et al. 2020). It is crucial to assess the impact of shifting to online teaching of anatomy on students based on their concerns and views, student knowledge, and professional capabilities. These studies will help the decision-makers to put plans either to switch to online anatomy teaching, apply blended learning combining campus and online teaching together, find a substitution for cadaveric specimens for the coming years (Brassett, Cosker et al. 2020).

Recently, it has been reported that COVID-19 lockdown negatively affected the academic performance of veterinary medical students and researchers (Mahdy 2020). Longhurst et al (Longhurst, Stone et al. 2020) analyzed the strength, weakness, opportunity, threat (SWOT) of the adaptations to anatomical education in the United Kingdom and Republic of Ireland during COVID-19 pandemic based on the perspectives of anatomical educators. The study highlighted several challenges, such as the lack of practical sessions, reduction of student engagement, and lack of technical support. Therefore, there is an essential need for academic collaboration, training on new technologies, inclusion of blended learning, free access to online resources, and development of alternative examination methods (Longhurst, Stone 
et al. 2020). The purpose of the current study was done to evaluate the students' experiences and attitudes regarding the online shift of veterinary anatomy learning during the first lockdown. The objectives were to determine:

1. The satisfaction level of the veterinary medical students with the sudden shift of anatomy learning during the first lockdown.

2. Is there any significant gender difference in the attitude of students regarding the sudden shift of anatomy learning during the first lockdown?

3. The main problems associated with the sudden shift of anatomy learning during the first lockdown.

\section{Materials And Methods}

The current cross-sectional study assessed the students' satisfaction with the remote teaching of veterinary anatomy during COVID-19 first lockdown using a survey questionnaire.

\section{Target population}

The target population of this study comprised students who were studying veterinary anatomy online during COVID-19 pandemic. Volunteer veterinary students who studied anatomy online during the pandemic were recruited through an announcement done via the "Veterinary Anatomy World" Facebook page (Facebook, Palo Alto, CA) operated by the author (https://www.facebook.com/VeterinaryAnatomyWorld) with about 32K followers mostly veterinary students. The aim of the study was clarified to the volunteer students, then they were asked to share the questionnaire link among their colleagues in their schools through the class Facebook and WhatsApp groups. The study was done during the period from June 4 to December 20, 2020.

\section{Ethical considerations}

Information about the aim of the questionnaire, voluntary participation, anonymity of participants, and data usage for research purposes were stated clearly at the beginning of the questionnaire. Participants were asked to provide their agreement, as a participant consent form, to participate in the study. The institutional ethics committee of Faculty of Veterinary Medicine, South Valley University, Egypt approved the study.

\section{Questionnaire design, validity, and reliability}

An online Google Form (Google LLC, Mountain View, CA) questionnaire was designed (shorturl.at/cuxHS). The validity of the questionnaire was checked in an initial pilot study on 25 students and their feedback was used to modify the questionnaire. Questionnaire reliability was 0.82 as indicated by Cronbach's alpha test. 
The questionnaire consisted of 20 questions. It was divided into two sections. The first section covered the students' demographic details, such as sex, age, country, university, and grade. It included 4 closed-ended and 2 open-ended questions. The second section evaluated the students' perception regarding the online learning of anatomy during COVID-19 pandemic, such as their interest in studying anatomy online, satisfaction with online learning, device used to access the online materials, type of the provided studying materials, comfortability with technological skills, degree of understanding, the learning tools used, the average studying hours before and during lockdown period, the possibility of replacing face-to-face teaching, and the most common problem detected during the online learning of anatomy. It included 13 closed-ended and 1 open-ended questions. Students were asked to write their thoughts about the shift to remote teaching of anatomy as a free text answer at the end of the questionnaire. To measure the individual opinion of student (i.e., interest, comfortability, satisfaction, agreement, or understanding), a 4-point Likert scale that ranged from (strongly disagree $=1$ to strongly agree $=4$ ) was used (Mulyanti, Purnama et al. 2020).

\section{Data collection and statistical analysis}

The minimum number of participants (sample size) was calculated to be 384 participants (Dean, Sullivan et al. 2013). Data collection was done using a spreadsheet linked to the online Google Form questionnaire. The data were exported to Microsoft Excel sheet (Microsoft Excel, Microsoft Corp., Redmond, WA)

The data were analyzed using SPSS version 21.0 (IBM Corp., Armonk. NY). The Shapiro-Wilk test was used to assess the normal distribution of data. Descriptive statistics were analyzed, and the percentage, frequencies, mean (M) and standard deviation (SD) of each scale was calculated. The ordinal data obtained from the student responses were converted to numeric values as follows (strongly agree $=4$ points; agree $=3$ points; disagree $=2$ points; strongly disagree $=1$ point) (Mayer and Cavallaro 2019), and the mean \pm SD was calculated. The independent t-test was used to compare the differences between the scores for male and female students, and the effect size (Cohen's d) was calculated. The statistical difference was indicated when $P<0.05$. Thematic analysis was used for open-ended questions.

\section{Results}

\section{Socio-demographic characteristics of participants}

A total of 974 students participated in the present study. However, 13 students did not agree to be included in the study, therefore they were excluded. The final number of participants was 961 coming from 87 countries and 6 continents with about $94.67 \%$ of the participants agreed to be included in the study (Table. 1). The distribution of the participants across the continents was as follows: the majority of students were from Asia (34.96\%), followed by Africa (24.35\%), Europe (20.29\%), Australia (7.80\%), North America (6.45\%), South America (5.83\%), and Oceania (New Zeeland, $0.31 \%)$. Most of the participants 
were female (55.88\%). The mean age of participants was $22.00 \pm 3.42$ years (range from 18-36 years) with majority of participants (89\%) fall in the age range of $18-25$ years. Approximately $87 \%$ of the students were first-and second-year students (Table. 2). All participated students confirmed that they studied anatomy online during the lockdown period.

\section{Evaluation of students' perception regarding the online learning of anatomy during COVID-19 pandemic}

To evaluate the online learning of anatomy during lockdown, the students were asked to express their opinion using a 4-Point Likert Scale questions.

Data showed that the mean students' interest rate in studying anatomy online during the lockdown was $3.12 \pm 0.88$ with the majority of students $(81.58 \%)$ were interested in studying anatomy online during COVID-19 lockdown. The mean score for the male respondents was significantly higher than that of female respondents regarding the interest in studying anatomy online during COVID-19 lockdown ( $P=$ 0.000 , Cohen's $d=0.36$ ). In addition, the mean students' comfortability rate with the technological skills was $3.14 \pm 0.81$ with the majority of students $(82.21 \%)$ were comfortable with the technological skills (using the Computer, surfing the internet, downloading files, etc.....) during online studying of anatomy during the lockdown. There was no statistically significant difference between the mean score for the male and female respondents regarding the comfortability with the technological skills $(P=0.057$, Cohen's $d=0.12$ ). Furthermore, the mean students' understanding rate of online learning of anatomy during lockdown was $2.62 \pm 0.84$. The majority of students $(60.46 \%)$ reported that they can understand anatomy well using online learning during the lockdown. The mean score for the male respondents was significantly higher than that of female respondents regarding the understanding rate of online learning of anatomy during lockdown ( $P=0.000$, Cohen's $d=0.36)$ (Fig. 1).

The studying materials provided to students were mostly in the form of Portable Document Format (pdf), followed by PowerPoint presentations with recorded voice, online streaming using video conferencing software's (such as Moodle, Zoom, and blackboard), 3D animation, dissection videos made by staff members, anatomy books, and handouts (Fig. 2). The mean student satisfaction rate with the provided studying materials was $2.66 \pm 0.86$. The mean score for the male respondents was significantly higher than that of female respondents regarding the satisfaction rate with the provided studying materials $(P=0.000$, Cohen's $d=0.40$ ). Although, about two-thirds of students $(60.46 \%)$ reported their satisfaction with the provided studying materials, the majority of students $(93.24 \%)$ reported their need for additional studying materials to help them understanding the provided lessons of anatomy (Fig 1).

\section{The tools used for online learning of anatomy}

To understand anatomy during COVID-19 lockdown, students used several online tools. Of these tools, YouTube videos and anatomy textbooks were the most used tools. The other tools were as follows: educational websites, anatomy Facebook pages, educational applications, research papers, anatomy E. books, anatomy WhatsApp groups, and anatomy telegram channels (Fig. 3). Regarding the electronic 
device used to connect to the virtual system were as follows: smartphone (42.07\%) followed by laptop (38.08\%), personal computer (10.85\%), and tablet (9.00\%).

\section{Students' opinion regarding studying anatomy online during lockdown}

The current results showed that approximately $52.76 \%$ of students believed that online learning of anatomy was most suitable for theoretical parts, about $8.74 \%$ of students believed that online learning of anatomy was most suitable for practical parts, and about $30.28 \%$ of students believed that online learning of anatomy was most suitable for both theoretical and practical parts. While $8.22 \%$ of students believe that online learning of anatomy was suitable for neither theoretical nor practical parts. On the contrary, about $36.63 \%$ of students thought that online learning of anatomy could replace face-to-face teaching (Fig. 1). Here are quotations from students' opinion regarding studying anatomy online during lockdown:

\section{Students who support online learning of anatomy}

Students who appreciated studying at home during the pandemic reported several reasons, such as flexibility, study in a comfortable space at home, study at convenient times, and saving travel time.

"E learning is the best choice during pandemic, we should try to make it lively and interactive", "Online learning is a great tool to supplement our current curriculum due to the flexibility and wide array of sources it allows us, but it is difficult to replace being able to dissect and work with a cadaver", "I'm very happy and comfortable with online learning of anatomy during the pandemic", "It gives me more time to revise the lectures which makes me understood the content more", "I think it's a good approach to deliver online classes materials to the students because something is better than nothing", "I like e-learning better as you can go at your own pace and go back when needed", "e-learning is a good refresher or an extra to your normal studies, and vice-versa. E-learning can be a nice introduction to the anatomy class/training sessions"

\section{Students who oppose online learning of anatomy}

Students who opposed studying at home during the pandemic reported several reasons, such as difficulty of staying concentrated, less interactive, and lack of hands-on experience.

"It really isn't an ideal mode of teaching, but it is better than nothing during this time. I much prefer face to face teaching as I find it difficult to engage with online material", "It is actually a good method, but I don't prefer it because it is hard to focus and also interaction is still essential for further learning of the lesson", "It was really hard to orient myself inside the body and determine relationships of structures" "online learning in anatomy had not prepared me for real life situations and the practical version of the class should be reestablished", "I do not prefer anatomy e-learning courses because it is a practical subject, you need to experience learning it in person than just staring at the picture because there's really a difference 
in learning theoretically and experiencing it", "It is physically exhausting and mentally draining", "I just finished and get passed the subject of anatomy because I complied my requirements on my chosen subject. Unfortunately, I didn't fully learn", "nothing can replace the knowledge that you earn touching and dissecting specimens", "Trying to understand 3D things in 2D was very difficult", "It is difficult to be surgeons without dissecting a specimen or learning topography", "It is extremely hard to learn anatomy without physically being able to manipulate physical structures such as bones and muscles".

\section{The average studying hours of anatomy before and during lockdown}

The average studying hours of anatomy decreased during COVID-19 lockdown compared to the period before the lockdown. The percentage of students who spent 3-4 hr/week, 5-6 hr/week, 7-8 hr/week, 8-10 $\mathrm{hr} /$ week studying anatomy during COVID-19 lockdown decreased by $6.74 \%, 6.19 \%, 0.99 \%$, and $2.32 \%$ compared to the period before the lockdown, respectively. Meanwhile, the percentage of students who spent 1-2 hr/week and 10-12 hr/week studying anatomy during COVID-19 lockdown increased by $13.26 \%$ and $2.98 \%$, respectively (Fig. 4B).

\section{The problems associated with studying anatomy online during lockdown}

The most common problems associated with online learning of anatomy were categorized in the following themes together with quotations from students' opinion regarding problems of studying anatomy online during lockdown (Fig. 4C):

1. The necessity for training lecturers on the E. Learning communication skills

- "Lecturers should be well-trained on how to use technology",

2. Lack of interaction compared to face-to-face teaching

- "I think anatomy is best learnt and understood by interaction with the lecturer because it is more practical than theoretical"

- "It is hard to interact with classmates, and learning becomes a very solo activity"

- "I lack motivation when I'm home all the time"

3. Internet connection-related issues

The Internet connection-related had a negative effect on not only the emergency remote learning, but also on the overall online learning experience. Students mentioned several difficulties related to Internet connections, such as poor or interrupted connection, especially in rural areas and the cost of Internet packages.

- "I can't understand the topic properly due to poor internet connection both from us and the professor" 
- "It is hard to understand due to poor network"

- "I usually find it difficult in access high speed internet, hence I find myself missing classes due to technical problems"

- "It is hard to purchase bundles due to the pandemic"

4. The need for much time to understand compared to face-to-face teaching

- "it takes more time to understand what the lecturer is teaching without the actual specimen"

- "I definitely have had to spend more time trying to orientate myself and understanding it",

5. Waiting for a long time to get feedback from the lecturer.

Spending long hours waiting to get feedback from the lecturers negatively influenced the students' motivation.

- "I think online learning leaves questions in the air"

- "Teachers have to reply on time to our questions"

\section{Students' suggestions to improve the online teaching of anatomy}

1 - Improvement of the provided study materials

- "Three-dimensional (3D) models and high-quality video presentations are required"

- "Using diagrams and good colored pic of the structures"

- "Diffuse lighting filters are needed during recording or live streaming to allow detail to be seen on camera"

- "Rehearse and record videos before online streaming to help bring questions before the session as these prevent bandwidth issues and losing detail"

2 - Enhancement of teaching skills and teaching methods

- "Training of lecturers on how to use online teaching applications"

- "Provide training on effective communication skills"

- "Provide questions after every lecture to test students' understanding"

- "Increase the interaction between students and lecturers"

- "The theoretical parts can stay online, but weekly sessions using cadavers should be mandatory again"

- "It requires a more practical approach other than theory to fully grasp the concepts"

- "online review, quizzes, videos and other learning platforms to learn anatomy in our own houses would be a great help for us veterinary students" 
3- Improvement of internet services

- "Provide a stable internet connection at cheaper rates for students during lockdown period"

- "Students should be provided with free internet packages during pandemic period".

- "Reliable internet connection should be available to all students",

\section{Discussion}

The present study explores the perception of veterinary medical students regarding the online learning of anatomy during the COVID-19 pandemic period. Recently, it has been reported that COVID-19 pandemic has negatively influenced the academic performance of veterinary medical students and researchers (Mahdy 2020). However, there is no study evaluated the shift to remote teaching of anatomy during the COVID-19 pandemic worldwide, therefore, the present study provides an assessment of the shift to remote teaching of veterinary anatomy during the COVID-19 pandemic based on students' perception.

The present data showed that the majority of students (81.6\%) were interested in studying anatomy online during COVID-19 lockdown, approximately $82 \%$ of students were comfortable with the technological skills, and approximately $61 \%$ of students can understand anatomy well using online learning. The capacity of medical students to engage in online learning was affected by several factors, such as gender, age, academic level, annual income, internet access, and the number of hours spent on online learning before pandemic (Baticulon, Alberto et al. 2020). In this regard, only 9\% of medical and dental students were fully satisfied with studying anatomy via virtual classes, whereas $55 \%$ were moderately satisfied (Singal, Bansal et al. 2020)

The studying materials provided to students were in the form of pdf, PowerPoint presentations with recorded voice, online streaming, and 3D animation. Online lectures are delivered through two main methods; synchronous and asynchronous teaching (Rashid, Rashid et al. 2020). The synchronous teaching (done in real-time using virtual classroom) is the most dominant form to deliver online lectures (Aristovnik, Keržič et al. 2020). This method offers more interaction between students and teachers, however, a high-speed and stable internet connection is required (Mohmmed, Khidhir et al. 2020). While in the asynchronous form of teaching the lectures are available in several forms, including PowerPoint presentations, pdf format, video recording, and audio recording (Aristovnik, Keržič et al. 2020). These different forms are either sent to students or be available through university platforms (Aristovnik, Keržič et al. 2020, Mahdy 2020). Students prefer an asynchronous mode of teaching than attending live lectures due to its flexibility and convenience with internet-related issues (Cardall, Krupat et al. 2008, Rashid, Rashid et al. 2020).

Prerecorded lecturers are more preferable by students in studying anatomy due to several reasons: students can listen and understand without worry of taking notes, the possibility to repeat the parts that they did not understand well, the ability for each student to learn at his own pace, students can listen to 
the lecture at the convenient time to them, and the ability to pause and take notes when needed (Cuschieri and Calleja Agius 2020, Mishra, Gupta et al. 2020). However, the main disadvantages of the pre-recorded lectures include lack of interaction between the lecturer and students and the absence of immediate response to students' queries (Cuschieri and Calleja Agius 2020). On the other hand, posting only presentations is not recommended (Puljak, Čivljak et al. 2020).

To understand anatomy during COVID-19 lockdown, students used several online tools such as, anatomy e-books, YouTube videos, educational websites, anatomy Facebook pages, educational applications, research papers, anatomy WhatsApp groups, and anatomy telegram channels. Students use several web-based platforms to find anatomical information, such as social media platforms, internet search engines, and anatomy e-books (Barry, Marzouk et al. 2016). Social media have been reported as an educational tool for teaching of anatomy, pathology, mathematics, and computing education to undergraduate students (Jaffar 2012, Osaigbovo 2018, Agbo, Olawumi et al. 2020, Mulenga and Marbàn 2020, Mustafa, Taha et al. 2020). Using social media in educational purposes helps the students to share knowledge and information with their colleagues, enhance their academic performance, and to improve their skills in reading and writing (Palla Ishfaq and Sheikh 200). The availability and popularity of YouTube makes it an effective educational tool for studying medical anatomy (Jaffar 2012, Barry, Marzouk et al. 2016, Mustafa, Taha et al. 2020). Social media platforms operated by anatomy teachers are considered as promising education tools through which trusted information are delivered, meanwhile, students can interact, inquire, and discuss with experts (Barry, Marzouk et al. 2016, Hennessy, Royer et al. 2020). WhatsApp and Facebook were the most favorite social media platform for learning of computing education in Nigeria. They help student's interaction and effective collaboration of students with their peers and teachers (Agbo, Olawumi et al. 2020). Integration of different social media platforms (Facebook, YouTube, and WhatsApp) in the teaching of mathematics to undergraduate students reflect a positive attitude of teachers in Zambia (Mulenga and Marbàn 2020). In addition, students participating in Facebook groups with tutor assistance showed a better understanding of the academic concepts and theories (Cuesta, Eklund et al. 2016). On the other hand, it is important to design technological pedagogical content that meet the diverse needs of the university students (Hossain, Ying et al. 2020).

Regarding the electronic device used to connect to the virtual system were as follows: smartphone (42.07\%) followed by laptop (38.08\%), personal computer (10.85\%), and tablet $(9.00 \%)$. It has been reported that medical students who use mobile devices in studying anatomy have a higher learning experience than others (Lazarus, Sookrajh et al. 2017). Previous studies showed that smartphones are the most commonly used device by leaners followed by laptop, desktop, and tablet (Baticulon, Alberto et al. 2020, Hossain, Ying et al. 2020). In addition, the majority of students have more than one electronic device (Hossain, Ying et al. 2020). Unequal access to computers and internet by students leads to the loss of effectiveness of the online learning (Xu and Xu 2019).

Although nearly two thirds of students showed their interest in studying anatomy online, and a majority of students believe that this type of learning was most suitable for either theoretical or practical parts or both, less than half of students believed that online learning of anatomy could replace face-to- 
face teaching. A recent study evaluated the shift to remote teaching of human anatomy in the University of Malta during Covid-19 pandemic showed that about half of the students thought that remote teaching of anatomy is equivalent to face-to-face teaching (Cuschieri and Calleja Agius 2020). Singal et al (Singal, Bansal et al. 2020) reported that medical and dental students are interested to study brain specimens in hand, while more than two thirds of students feel difficulty in understanding embryology without models. The authors added that students missed several aspects of anatomy education, such as dissection lab, histology lab, face-to-face lectures, interaction with their mentors, and discussion with their classmates (Singal, Bansal et al. 2020). A study done on undergraduate medical students in India revealed that about $31 \%$ of students prefer classroom learning only, $16 \%$ prefer online learning only while $53 \%$ prefer a combination of both methods (Shetty, Shilpa et al. 2020). Students' preference of classroom learning is due to student teacher interaction, acquiring practical skills, and development of communication skills, while students' preference to online learning is due to its easy participation, and time investment (Shetty, Shilpa et al. 2020). On the other hand, students showed a significantly higher achievement with blended learning mode than those engaged in E-learning mode only (Al-Qahtani and Higgins 2013). Blended learning mode enables students to express more learning in classroom discussion, personal interaction with tutors, and assignments than in E-Learning which depends only on on-line content (Hameed, Badii et al. 2008). Furthermore, combination of traditional teaching methods with E-learning methods improved the performance and learning outcomes of nursing students (Sheikhaboumasoudi, Bagheri et al. 2018). Therefore, it is recommended to apply blended learning after the pandemic to achieve the advantages of both online and traditional teaching.

Different learning styles have been reported; visual (learning mainly through seeing), auditory (learn mainly through hearing), read and write (learning mainly through read and write), and kinesthetic (learning mainly through touching, moving, and doing) learning styles (VARK) (Fleming and Baume 2006, Hussain 2017). Previous studies showed that the majority of the medical and veterinary students were multimodal (Lujan and DiCarlo 2006, Neel and Grindem 2010, Nuzhat, Salem et al. 2011, Kharb, Samanta et al. 2013, Ojeh, Sobers-Grannum et al. 2017). On the other hand, the single preferred learning styles of medical students is visual style (Lujan and DiCarlo 2006, Buşan 2014), auditory style (Nuzhat, Salem et al. 2011, Peyman, Sadeghifar et al. 2014), read and write style (Ojeh, Sobers-Grannum et al. 2017), and kinesthetic style (Kharb, Samanta et al. 2013). The current results showed that students recommended to add videos, pictures, and diagrams to the presentations because anatomy is more practical subject. Moreover, they recommended to provide audio recording with the text. It is recommended that educators should design their courses and teaching modes to meet the students' learning needs and preferred learning style (Ojeh, Sobers-Grannum et al. 2017).

Several challenges were faced by students in adapting to online learning of anatomy during COVID-19 pandemic. Our results agree with the major challenges reported in other studies, such as the unstable network connection, lack of resources to join online learning, interrupted electricity connection, social isolation, eye strain, and lack of appropriate learning environment at home with presence of more distractions that hinder their studies (Baticulon, Alberto et al. 2020, Cuschieri and Calleja Agius 2020, Mishra, Gupta et al. 2020, Shetty, Shilpa et al. 2020, Choudhary 2021). In addition, the lack of motivation 
has been reported as a major problem with online learning due to lack of immediate feedback from teachers (Mishra, Gupta et al. 2020). Furthermore, spending long time daily in online classes using mobile phones induces overwhelming stress and several health issues (Sundarasen, Chinna et al. 2020). These challenges affect the students' studying patterns, as well as, wellbeing (Cuschieri and Calleja Agius 2020). It has been reported that students need more time to comprehend online learning materials than ordinary learning methods (Baticulon, Alberto et al. 2020). It is recommended that the university authorities should organize programs, rewards, or financial aids to help students to cope with mental and financial stressors due to lockdown (Nurunnabi, Hossain et al. 2020).

\section{Limitations of the study}

This study has a number of limitations. This study focused to evaluate the students' experience with the online shift of veterinary anatomy learning during the COVID-19 pandemic; therefore, further research on different subjects of the veterinary curriculum could reveal different insights. The results of this study were based on the experience of university students, who might change their perceptions for a number of reasons. In addition, several countries were represented by a few numbers of participants as not all target students were reached. However, their inclusion in the study helped to get a global and diverse overview. Since the questionnaire invitation was distributed online, it is assumed that the students that are most active online that are most likely to see and respond to the invitation to participate and, by association, the most likely to prefer online learning. The findings may therefore not represent all anatomy students, but rather students with a higher online activity. Finally, the results of this study focused on differences between genders.

\section{Concluding Remarks}

The current study evaluated the shift to remote teaching of veterinary anatomy during the COVID-19 pandemic lockdown based on the students' perspectives. Shifting to remote teaching appears to be a good and convenient approach during the lockdown period as shown by student interest to study anatomy online during the COVID-19 lockdown, their comfortability with the technological skills, and their level of understanding. However, practical classes with cadaver dissection and dealing with different anatomical specimens is essential for veterinary students. The study also highlighted several challenges associated with studying anatomy online during the lockdown period and recommendation to overcome these challenges. Future studies in each country are recommended for better evaluation.

\section{Declarations}

\section{Acknowledgements}

The author would like to acknowledge all participants for their time, effort, and contributions. 


\section{Conflict of interest}

The author declares that the research was conducted in the absence of any commercial or financial relationships that could be construed as a potential conflict of interest.

\section{Funding}

No fund received for this study.

\section{Data Availability Statement}

The data are available upon request.

\section{References}

Agbo, F. J., O. Olawumi, S. Oyelere, D. E. K. Awuni, S. Olaleye, R. O. Agjei, D. Ukpabi, A. Yunusa, S. A. Gbadegeshin, L. Awoniyi, K. O. Erinle, E. Mogaji, C. E. Nwachukwu and A. Olawuni (2020). "Social media usage for computing education: The effect of the strength and group communication on perceived learning outcome." IJEDICT 16: 5-26.

Al-Qahtani, A. A. Y. and S. E. Higgins (2013). "Effects of traditional, blended and e-learning on students' achievement in higher education." J. Comput. Assist. Learn. 29(3): 220-234.

Aristovnik, A., D. Keržič, D. Ravšelj, N. Tomaževič and L. Umek (2020). "Impacts of the COVID-19 pandemic on life of higher education students: A global perspective." Sustainability. 12(20): 8438.

Barry, D. S., F. Marzouk, K. Chulak-Oglu, D. Bennett, P. Tierney and G. W. O'Keeffe (2016). "Anatomy education for the YouTube generation." Anat Sci Educ 9(1): 90-96.

Baticulon, R. E., N. R. I. Alberto, M. B. C. Baron, R. E. C. Mabulay, L. G. T. Rizada, J. J. Sy, C. J. S. Tiu, C. A. Clarion and J. C. B. Reyes (2020). Barriers to online learning in the time of COVID-19: A national survey of medical students in the Philippines. medRxiv.

Brassett, C., T. Cosker, D. C. Davies, P. Dockery, T. H. Gillingwater, T. C. Lee, S. Milz, S. H. Parson, F. Quondamatteo and T. Wilkinson (2020). "COVID-19 and anatomy: Stimulus and initial response." J Anat 237(3): 393-403. 
Buşan, A.-M. (2014). "Learning styles of medical students - implications in education." Curr Health Sci J. 40(2): 104-110.

Byrnes, K. G., P. A. Kiely, C. P. Dunne, K. W. McDermott and J. C. Coffey (2020). Communication, collaboration and contagion: "Virtualisation" of anatomy during COVID-19. Clin Anat.

Cardall, S., E. Krupat and M. Ulrich (2008). "Live lecture versus video-recorded lecture: are students voting with their feet?" Acad Med 83(12): 1174-11748.

Choudhary, O. P. (2021). "Consequences of the COVID-19 pandemic on veterinary anatomy education in India." Int. J. Morphol. 39(2): 623-624.

Cuesta, M., M. Eklund, I. Rydin and A.-K. Witt (2016). "Using Facebook as a co-learning community in higher education." Learn Media Technol. 41(1): 55-72.

Cuschieri, S. and J. Calleja Agius (2020). "Spotlight on the shift to remote anatomical teaching during Covid-19 pandemic: Perspectives and experiences from the University of Malta." Anat Sci Educ 13(6): 671-679.

Dean, A., K. Sullivan and M. Soe. (2013, updated 2013/04/06). "OpenEpi: Open Source Epidemiologic Statistics for Public Health, Version. ." Ed. 3.01. Retrieved 11/10, 2020, from www.OpenEpi.com.

Fleming, N. and D. Baume (2006). "Learning Styles Again: VARKing up the right tree!" J. Educ. Dev. 7(4): 4.

Franchi, T. (2020). "The impact of the Covid-19 pandemic on current anatomy education and future careers: A student's perspective." Anat Sci Educ 13(3): 312-315.

Guan, Y., H. Deng and X. Zhou (2020). "Understanding the impact of the COVID-19 pandemic on career development: Insights from cultural psychology." J. Vocat. Behav 119: 103438-103438.

Haleem, A., M. Javaid and R. Vaishya (2020). "Effects of COVID-19 pandemic in daily life." J Curr Med Res Pract 10(2): 78-79.

Hameed, S., A. Badii and A. Cullen (2008). Effective e-learning integration with traditional learning in a blended learning environment. European and mediterranean conference on information systems.

Hennessy, C. M., D. F. Royer, A. J. Meyer and C. F. Smith (2020). "Social media guidelines for anatomists." Anat Sci Educ 13(4): 527-539.

Hossain, S. F. A., Y. Ying and S. K. Saha (2020). Systematic mobile device usage behavior and successful implementation of TPACK based on university students need. Advances in computer vision (Proceedings of the 2019 Computer Vision Conference ( $(\underline{V C})$, Volume 1). K. Arai and S. Kapoor. Cham, Springer International Publishing. 1: 729-746. 
Hussain, I. (2017). "Pedagogical implications of VARK model of learning/Hussein." Int. J. Lit. Lang. Ling. 38: 33-37.

Jaffar, A. A. (2012). "YouTube: An emerging tool in anatomy education." Anat Sci Educ 5(3): 158-164. Kapasia, N., P. Paul, A. Roy, J. Saha, A. Zaveri, R. Mallick, B. Barman, P. Das and P. Chouhan (2020). "Impact of lockdown on learning status of undergraduate and postgraduate students during COVID-19 pandemic in West Bengal, India." Child. Youth Serv. Rev. 116: 105194-105194.

Kharb, P., P. P. Samanta, M. Jindal and V. Singh (2013). "The learning styles and the preferred teachinglearning strategies of first year medical students." J Clin Diagn Res 7(6): 1089-1092.

Lazarus, L., R. Sookrajh and K. S. Satyapal (2017). "Tablet technology in medical education in South Africa: a mixed methods study." BMJ Open 7(7): e013871.

Li, Q., X. Guan, P. Wu, X. Wang, L. Zhou, Y. Tong, R. Ren, K. S. M. Leung, E. H. Y. Lau, J. Y. Wong, X. Xing, N. Xiang, Y. Wu, C. Li, Q. Chen, D. Li, T. Liu, J. Zhao, M. Liu, W. Tu, C. Chen, L. Jin, R. Yang, Q. Wang, S. Zhou, R. Wang, H. Liu, Y. Luo, Y. Liu, G. Shao, H. Li, Z. Tao, Y. Yang, Z. Deng, B. Liu, Z. Ma, Y. Zhang, G. Shi, T. T. Y. Lam, J. T. Wu, G. F. Gao, B. J. Cowling, B. Yang, G. M. Leung and Z. Feng (2020). "Early transmission dynamics in Wuhan, China, of novel coronavirus-infected pneumonia." N Engl J Med 382(13): 1199-1207.

Longhurst, G. J., D. M. Stone, K. Dulohery, D. Scully, T. Campbell and C. F. Smith (2020). "Strength, Weakness, Opportunity, Threat (SWOT) analysis of the adaptations to anatomical education in the United Kingdom and Republic of Ireland in response to the Covid-19 pandemic." Anat Sci Educ 13(3): 301-311.

Lujan, H. L. and S. E. DiCarlo (2006). "First-year medical students prefer multiple learning styles." Adv Physiol Educ 30(1): 13-16.

Mahdy, M. (2020). "The impact of COVID-19 pandemic on the academic performance of veterinary medical students." Front. Vet. Sci.

Mahdy, M., W. Younis and Z. Ewaida (2020). "An overview of SARS-CoV-2 and animal infection." Front. Vet. Sci. 7: 1-12.

Marelli, S., A. Castelnuovo, A. Somma, V. Castronovo, S. Mombelli, D. Bottoni, C. Leitner, A. Fossati and L. Ferini-Strambi (2020). Impact of COVID-19 lockdown on sleep quality in university students and administration staff. J. Neurol.

Mayer, J. D. and R. Cavallaro (2019). Brief Mood Introspection Scale (BMIS): Technical and scoring manual (3rd Edition), UNH Personality lab: 29.

Mishra, L., T. Gupta and A. Shree (2020). "Online teaching-learning in higher education during lockdown period of COVID-19 pandemic." Int. J. Educ. Res Open 1: 100012. 
Mohmmed, A. O., B. A. Khidhir, A. Nazeer and V. J. Vijayan (2020). Emergency remote teaching during Coronavirus pandemic: the current trend and future directive at Middle East College Oman. Innov. Infrastruct. Solut. 5: 72.

Mukhtar, K., K. Javed, M. Arooj and A. Sethi (2020). "Advantages, limitations and recommendations for online learning during COVID-19 pandemic era." Pak J Med Sci 36: S27-S31.

Mulenga, E. M. and J. M. Marbàn (2020). "Social media usage among pre-service secondary mathematics teachers in Zambia." JRAMathEdu: 130-147.

Mulyanti, B., W. Purnama and R. E. Pawinanto (2020). "Distance learning in vocational high schools during the covid-19 pandemic in West Java province, Indonesia." Indones. J. Sci. Technol 5(2): 271-282.

Mustafa, A. G., N. R. Taha, O. A. Alshboul, M. Alsalem and M. I. Malki (2020). "Using YouTube to learn anatomy: Perspectives of Jordanian medical students." Biomed Res. Int. 2020: 8 pages.

Neel, J. A. and C. B. Grindem (2010). "Learning-style profiles of 150 veterinary medical students." J Vet Med Educ 37(4): 347-352.

Nurunnabi, M., S. Hossain, K. Chinna, S. Sundarasen, H. B. Khoshaim, K. Kamaludin, G. M. Baloch, A. Sukayt and X. Shan (2020). "Coping strategies of students for anxiety during the COVID-19 pandemic in China: a cross-sectional study." F1000Res 9: 1115.

Nuzhat, A., R. O. Salem, M. S. Quadri and N. Al-Hamdan (2011). "Learning style preferences of medical students: a single-institute experience from Saudi Arabia." Int J Med Educ 2: 70-73.

Ojeh, N., N. Sobers-Grannum, U. Gaur, A. Udupa and M. A. A. Majumder (2017). "Learning style preferences: A study of pre-clinical medical students in Barbados." J Adv Med Educ Prof. 5(4): 185-194.

Osaigbovo, I. (2018). "Leveraging social media for pathology education: Patterns and perceptions among undergraduates." Ann Trop Pathol 9(2): 139-144.

Pak, A., O. A. Adegboye, A. I. Adekunle, K. M. Rahman, E. S. McBryde and D. P. Eisen (2020). "Economic consequences of the COVID-19 outbreak: the need for epidemic preparedness." Front. Public Health 8(241).

Palla Ishfaq, A. and A. Sheikh (200). "Impact of social media on the academic performance of college students in Kashmir." Inf Discov Deliv: https://doi.org/10.1108/IDD-1106-2020-0061.

Pather, N., P. Blyth, J. A. Chapman, M. R. Dayal, N. A. M. S. Flack, Q. A. Fogg, R. A. Green, A. K. Hulme, I. P. Johnson, A. J. Meyer, J. W. Morley, P. J. Shortland, G. Štrkalj, M. Štrkalj, K. Valter, A. L. Webb, S. J. Woodley and M. D. Lazarus (2020). "Forced disruption of anatomy education in Australia and New Zealand: An acute response to the Covid-19 pandemic." Anat Sci Educ 13(3): 284-300. 
Peyman, H., J. Sadeghifar, J. Khajavikhan, M. Yasemi, M. Rasool, Y. M. Yaghoubi, M. M. H. Nahal and H. Karim (2014). "Using VARK approach for assessing preferred learning styles of first year medical sciences students: A Survey from Iran." J Clin Diagn Res 8(8): GC01-GC04.

Puljak, L., M. Čivljak, A. Haramina, S. Mališa, D. Čavić, D. Klinec, D. Aranza, J. Mesarić, N. Skitarelić, S. Zoranić, D. Majstorović, M. Neuberg, Š. Mikšić and K. Ivanišević (2020). "Attitudes and concerns of undergraduate university health sciences students in Croatia regarding complete switch to e-learning during COVID-19 pandemic: a survey." BMC Med Educ 20(1): 416.

Rashid, A. A., M. R. A. Rashid, M. N. Yaman and I. Mohamad (2020). "Teaching medicine online during the COVID-19 pandemic: A Malaysian Perspective." Bangladesh J. Med. Sci 19: S 77-S 81.

Romero-Blanco, C., J. Rodríguez-Almagro, M. D. Onieva-Zafra, M. L. Parra-Fernández, M. D. C. PradoLaguna and A. Hernández-Martínez (2020). "Sleep pattern changes in nursing students during the COVID19 lockdown." Int J Environ Res Public Health 17(14): 5222.

Ross, C. F., M. J. Pescitelli, H. F. Smith and J. M. Williams (2020). Teaching anatomy with dissection in the time of COVID-19 is essential and possible. Clin Anat, John Wiley \& Sons, Inc.: 10.1002/ca.23640.

Sahu, P. (2020). "Closure of universities due to Coronavirus Disease 2019 (COVID-19): Impact on education and mental health of students and academic staff." Cureus 12(4): e7541-e7541.

Sheikhaboumasoudi, R., M. Bagheri, S. A. Hosseini, E. Ashouri and N. Elahi (2018). "Improving nursing students' learning outcomes in fundamentals of nursing course through combination of traditional and elearning methods." Iran J Nurs Midwifery_Res 23(3): 217-221.

Shetty, S., C. Shilpa, D. Dey and S. Kavya (2020). "Academic crisis during COVID 19: Online classes, a panacea for imminent doctors." Indian J Otolaryngol Head Neck Surg.

Singal, A., A. Bansal, P. Chaudhary, H. Singh and A. Patra (2020). "Anatomy education of medical and dental students during COVID-19 pandemic: a reality check." Surg. Radiol. Anat.

Singh, K., U. Gaur, K. Hall, K. Mascoll, D. Cohall and M. Majumder (2020). "Teaching anatomy and dissection in an era of social distancing and remote learning." Adv Hum Biol 10(3): 90-94.

Sundarasen, S., K. Chinna, K. Kamaludin, M. Nurunnabi, G. M. Baloch, H. B. Khoshaim, S. F. A. Hossain and A. Sukayt (2020). "Psychological impact of COVID-19 and lockdown among university students in Malaysia: Implications and policy recommendations." Int. J. Environ. Res. Public Health 17(17): 6206.

UNESCO. (2020). "Education: From disruption to recovery." Retrieved 25/10, 2020, from https://en.unesco.org/covid19/educationresponse.

Wahab, A. (2020). "Online and remote learning in higher education institutes: A necessity in light of COVID-19 pandemic." J Higher Education 10(3): 16-25. 
WHO. (2019). "Coronavirus disease (COVID-19) Pandemic." Retrieved 02/01, 2021, from https://www.who.int/emergencies/diseases/novel-coronavirus-2019.

WHO. (2020). "WHO announces COVID-19 outbreak a pandemic." Retrieved 02/01, 2021, from https://www.euro.who.int/en/health-topics/health-emergencies/coronavirus-covid19/news/news/2020/3/who-announces-covid-19-outbreak-a-pandemic.

Xu, D. and Y. Xu (2019). "The promises and limits of online higher education: Understanding how distance education affects access, cost, and quality." American Enterprise Institute: 1-40.

\section{Tables}

Table. 1: Number of participants from different countries. 


\begin{tabular}{|c|c|c|c|c|c|c|c|}
\hline Country & Number & Country & ber & Country & Jumber & Country & Number \\
\hline Philippines & 119 & Algeria & 8 & Canada & 3 & Togo & 2 \\
\hline Australia & 75 & Senegal & 8 & Croatia & 3 & Tunisia & 2 \\
\hline Egypt & 74 & Indonesia & 7 & Guatemala & 3 & Bolivia & 1 \\
\hline Pakistan & 57 & South Africa & 7 & Ireland & 3 & Botswana & 1 \\
\hline India & 55 & Albania & 6 & Italy & 3 & Cameroon & 1 \\
\hline USA & 54 & Czech Republic & 6 & Mongolia & 3 & Costa Rica & 1 \\
\hline Romania & 38 & Denmark & 6 & New Zealand & 3 & Spain & 1 \\
\hline Nigeria & 36 & Iraq & 6 & Russia & 3 & Greece & 1 \\
\hline Mexico & 34 & Jordan & 6 & Slovakia & 3 & Japan & 1 \\
\hline Poland & 33 & Libya & 5 & Sri Lanka & 3 & Kosovo & 1 \\
\hline UK & 30 & Uganda & 5 & Sudan & 3 & Laos & 1 \\
\hline Zambia & 25 & Colombia & 5 & The Netherlands & 3 & Lithuania & 1 \\
\hline Nepal & 18 & Ethiopia & 4 & Austria & 2 & Namibia & 1 \\
\hline Bangladesh & 17 & Ukraine & 4 & Burkina Faso & 2 & Nicaragua & 1 \\
\hline France & 17 & Bulgaria & 4 & Ecuador & 2 & Palestine & 1 \\
\hline Somalia & 15 & Germany & 4 & Hungary & 2 & Paraguay & 1 \\
\hline Morocco & 13 & Ghana & 4 & Latvia & 2 & Portugal & 1 \\
\hline Belgium & 12 & Malaysia & 4 & Peru & 2 & Rwanda & 1 \\
\hline Kenya & 12 & Afghanistan & 3 & Serbia & 2 & Sweden & 1 \\
\hline Myanmar & 11 & Argentina & 3 & Syria & 2 & Tanzania & 1 \\
\hline Thailand & 10 & Turkey & 3 & Taiwan & 2 & UAE & 1 \\
\hline Brazil & 9 & Viet Nam & 3 & Timor-Leste & 2 & & \\
\hline
\end{tabular}

Table. 2 Sociodemographic characteristics of participants. 


\begin{tabular}{lllll} 
& & Number & Male & Female \\
& & $(\%)$ & $\mathbf{n}(\%)$ & $\mathbf{n}(\%)$ \\
\hline Educational level & $-1^{\text {st }}$ year students & $414(43.08 \%)$ & $175(18.21 \%)$ & $239(24.87 \%)$ \\
\hline & $-2^{\text {nd }}$ year students & $425(44.22 \%)$ & $195(20.29 \%)$ & $230(23.93 \%)$ \\
\hline & $-3^{\text {rd }}$ year students & $122(12.70 \%)$ & $54(5.62 \%)$ & $68(7.08 \%)$ \\
\hline Age (years) & Total number & $961(100 \%)$ & $424(44.12 \%)$ & $537(55.88 \%)$ \\
\hline & $18-20$ & $450(46.83 \%)$ & $173(18.00 \%)$ & $277(28.82 \%)$ \\
\hline & $21-25$ & $410(42.66 \%)$ & $191(19.88 \%)$ & $219(22.79 \%)$ \\
\hline & $26-30$ & $82(8.53 \%)$ & $45(4.68 \%)$ & $37(3.85 \%)$ \\
\hline & Above 30 & $19(1.98 \%)$ & $15(1.56 \%)$ & $4(0.42 \%)$ \\
\hline & Total number & $961(100 \%)$ & $424(44.12 \%)$ & $537(55.88 \%)$
\end{tabular}

\section{Figures}

Fig. 1

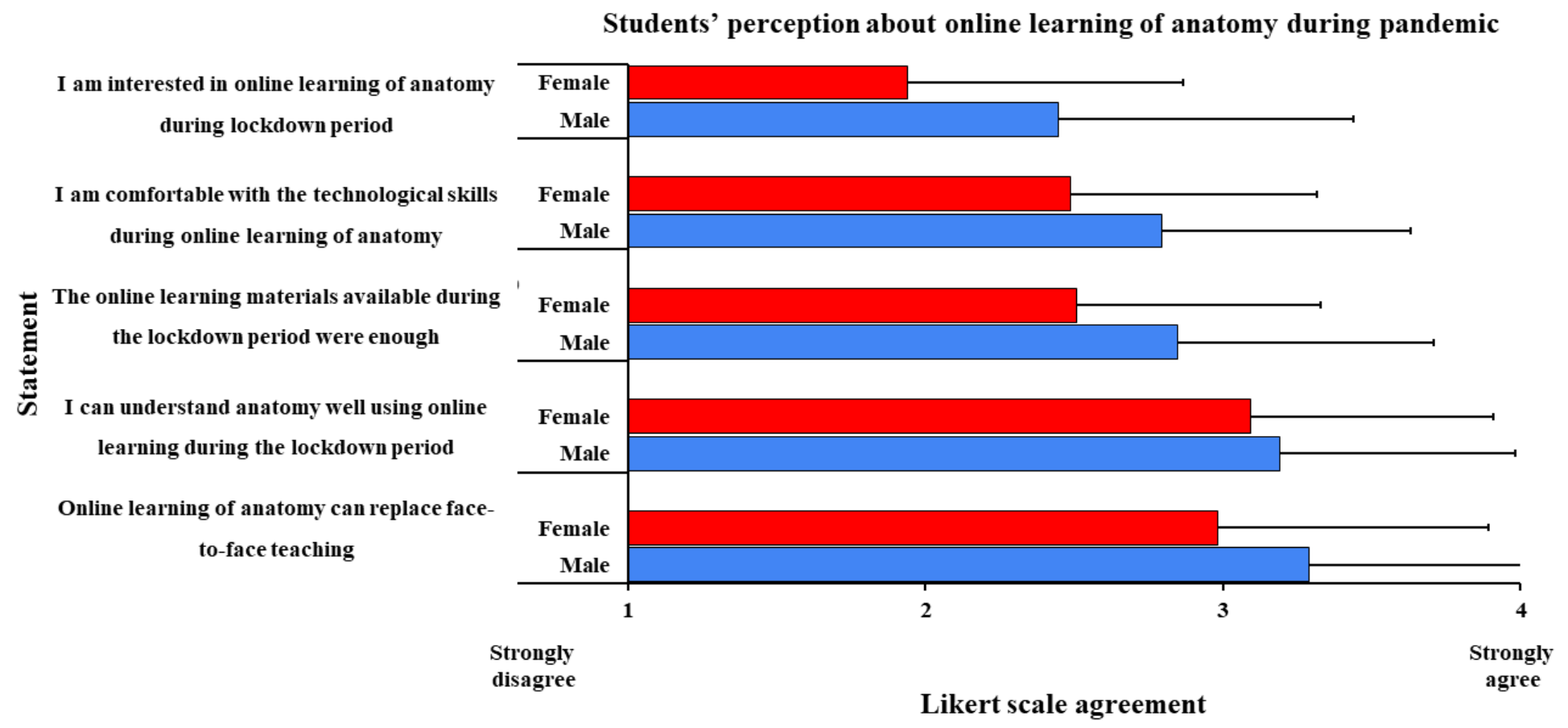

Figure 1 
Fig. 1: A diagram showing students' perception about online learning of anatomy during pandemic. Data were represented as Mean \pm SD.

Fig. 2

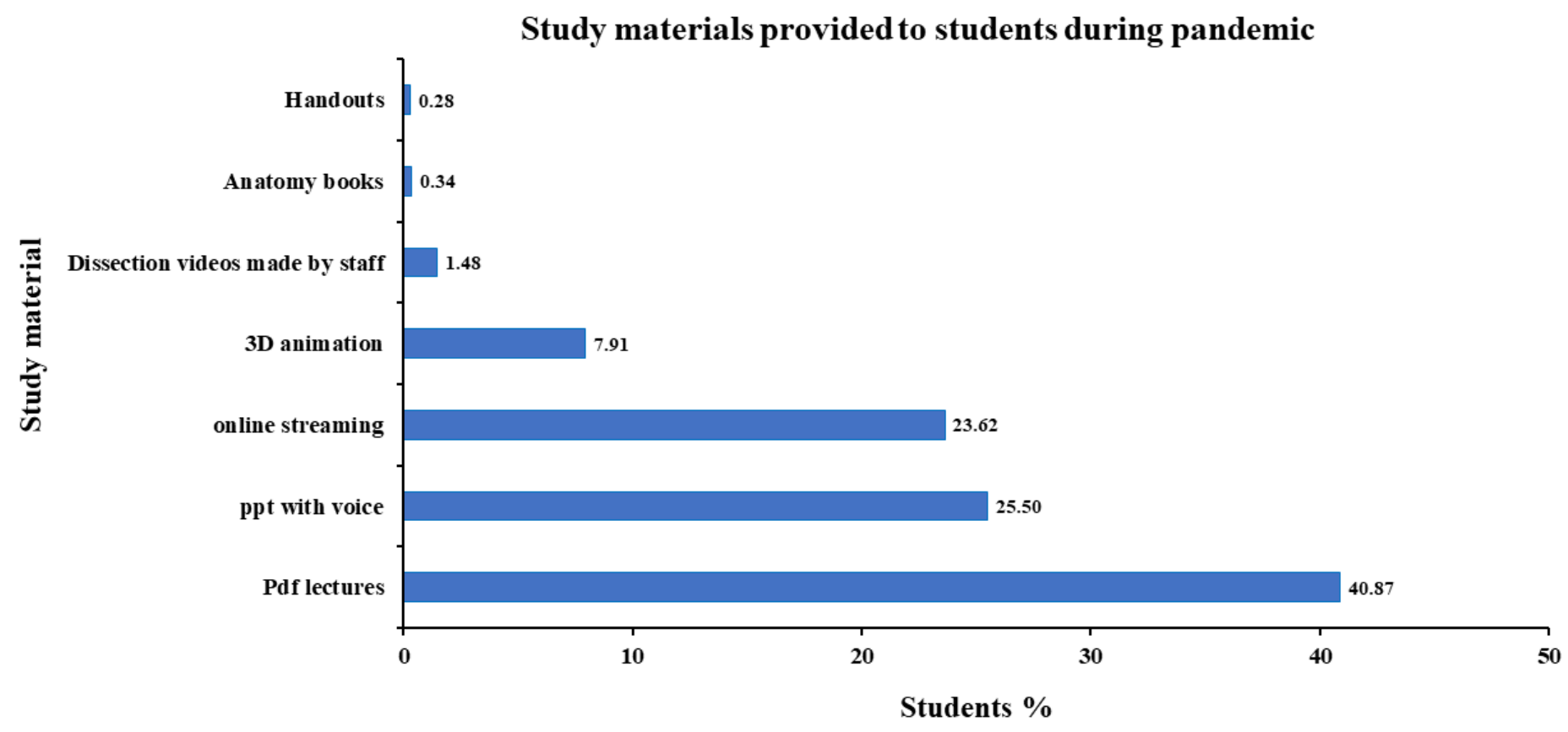

Figure 2

Fig. 2: A diagram showing the type of study material provided to students. 
Fig. 3

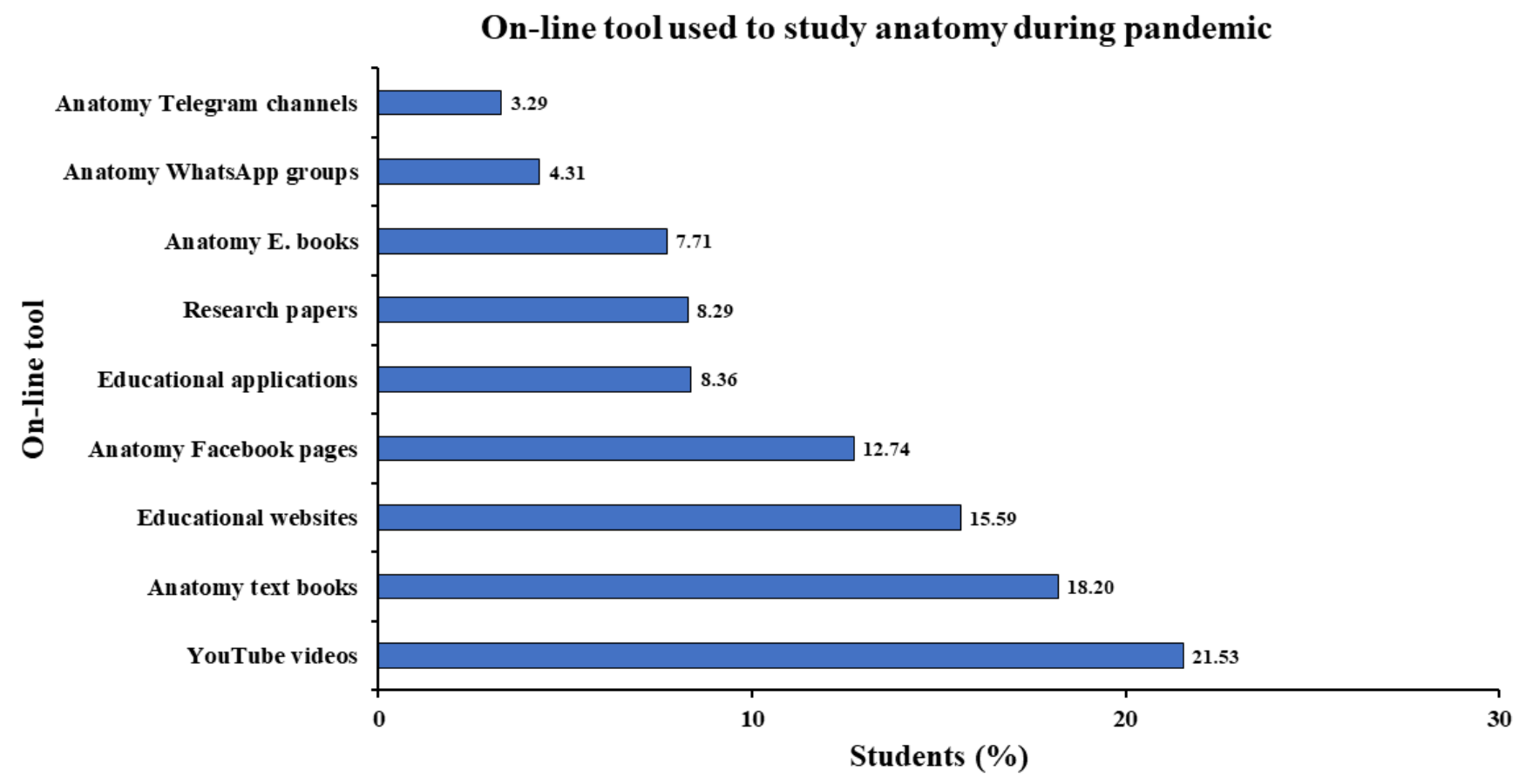

\section{Figure 3}

Fig. 3: A diagram showing the on-line tool used to study anatomy.

Fig. 4

\section{Average time spent in studying anatomy before and during pandemic}

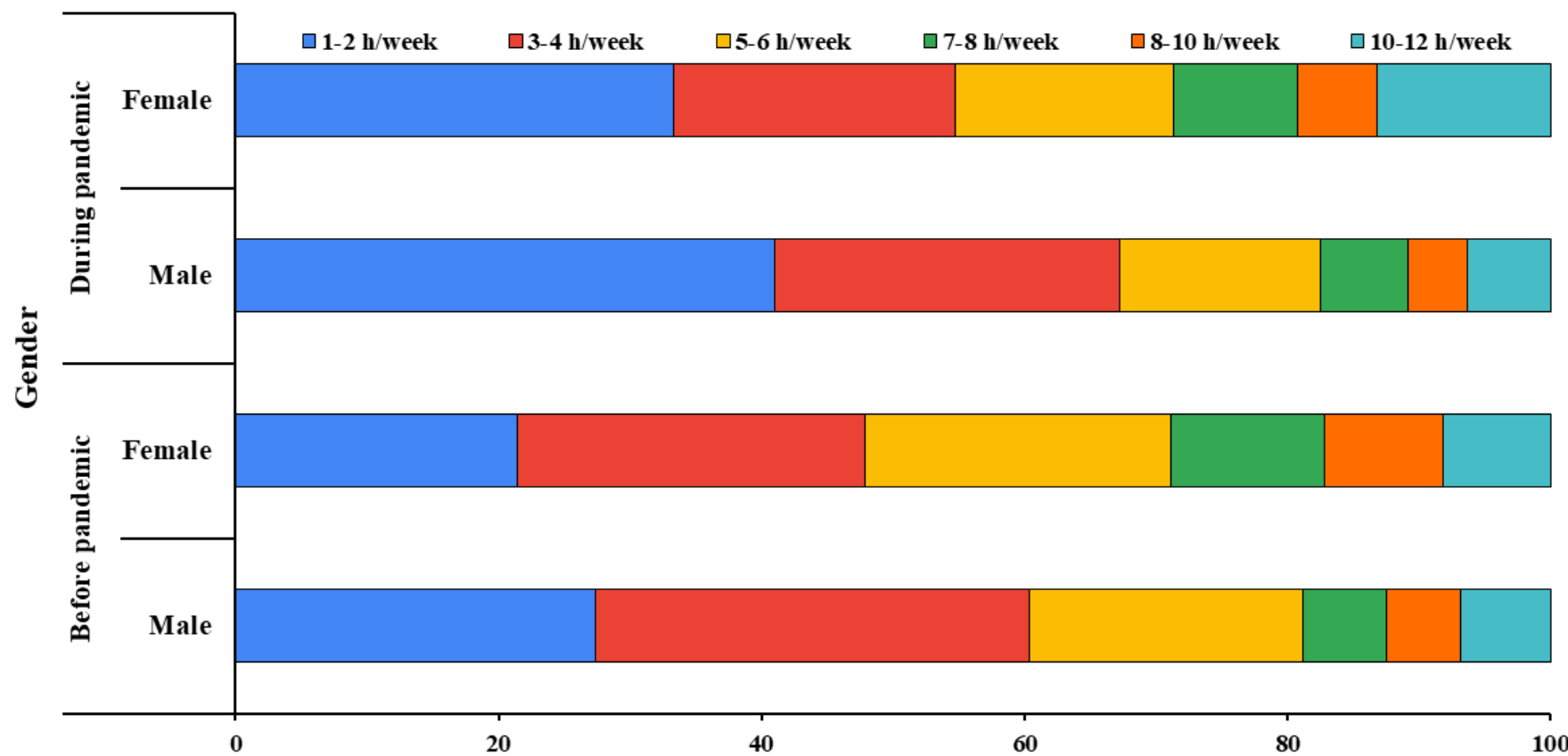

Students \% 
Figure 4

Fig. 4: Evaluation of average studying time of anatomy online before and during lockdown period. 